\title{
Impact of Strategy and Environmental Predictability on Financial Performance in Non- Governmental Organizations
}

\author{
Hasan Metin, $\mathrm{PhD}$
}

Esra Metin

\begin{abstract}
This study tries to understand the relationship among financial performance, environmental predictability and having strategy in the third (NGO) sector. The independent variable of the study is financial performance which is conceptualized as achieving the financial objectives which have been previously established. Environmental predictability is a sub-dimension of organizational environment that explains stability of the environment. Having strategy on the other hand is related with having mission and vision statements that are explicitly and clearly defined. The results of regression analysis indicate that, environmental predictability and having a clearly defined strategy have positive effects on financial performance in Non-Governmental Organizations.
\end{abstract}

Keywords: Financial Performance, Strategy, Environmental Predictability

\section{Introduction}

Strategy and environment are closely related in the management literature that organizations have varying strategies in different environmental complexities to be able to increase their performances (Miles,1980) and to be ab le to survive. Environmental predictability is a very significant factor for the organizations when determining their strategy to be able to answer the needs of the stakeholders and to achieve previously determined objectives.

\section{Performance}

Performance is a very broad concept that every kind of organization either profit seeking or not profit seeking; public or private measures, manages and tries to increase their performances. Performance measurement is a multi-dimensional issue that there are both financial and non-financial aspects of it. Since performance management in general is considered to have a financial emphasis meaning that as long as the organizations are considered to have high performance as long as they achieve the previously determined financial objectives, the non-financial dimension of performance management is not negligible.

Non-governmental or non-profit organizations rely on volunteerism that the financial expectations are less stressed in the third sector, whereas creating an added value for the humanity and civil attempts are taken as more important when conceptualizing the performance of non-profit or non-governmental organizations (Metin, 2017).

Since there are attempts towards conceptualizing performance within a broader perspective through determination of nonfinancial indicators for the profit seeking institutions, measurement of performance in the third sector has a financial dimension as well. Not profit seeking does not necessarily mean there is no financial dimension in the performance measurement of the NGOs. "Operating expense ratios, productivity measures, fundraising efficiency and the ability to acquire needed resources" (Ritchie \& Kolodinsky, 2003) are the indicators of the financial dimension of the performance management of the NGOs. Moreover, non-financial criteria as Kaplan (2001) stated like "quality of service provision, satisfaction of members/volunteers/staff, public image and program / service effectiveness have been acknowledged as playing a pivotal role influencing performance" (Tucker, 2015, p.318).

\section{Environment}

Robbins (1983) sees general environment as the "remainder of the universe from the subset that represents the organization" (Robbins, 1983, p. 143). Political factors, legal structure, social environment, and demographics should be 
considered under general environment (Koçel, 2011, p. 292; Robbins, 1983, p. 143; Jones, 2010, p. 85). Specific environment on the other can be defined as "the forces that are directly related to organization in its process of achieving goals" (Jones, 2010, p. 82; Robbins, 1983, p.143).

Environment in the management literature is presupposed to be the most crucial factor that determines the strategy and the organizational structure of an organization being profit seeking or non-profit seeking. Environment in the management literature has sub-dimensions such as environmental predictability, environmental complexity and environmental competitiveness. This study focuses specifically on environmental predictability and tries to understand its impact on financial performance along with strategy. Since strategy and environmental predictability are also highly related according to literature, the independent variable of the study has been taken as performance, since the ultimate purpose is increasing the performance for both profit seeking and not-profit seeking organizations.

\section{Strategy}

The literature as stated above links strategy (strategic choices and strategic processes) with environmental complexity, environmental uncertainty and environmental predictability. Ansoff (1972), Mintzberg (1979) and llinitch D'Aveni, and Lewin (1996) are the scholars that tried to understand the strategy and environment relations to increase the effectiveness of organizations. Chandler, (1962) defined strategy as "The determination of the basic long-term goals of an enterprise, and the adoption of courses of actions and the allocation of resources necessary to carry out these goals". Mintzberg (1979) defines "strategy is a mediating force between the organization and its environment: consistent patterns of streams of organizational decisions to deal with the environment".

Mission and vision statement are highly crucial for the organizations that clear and transparent definition of them enables all stakeholders to be explicitly informed about the strategic objectives of the organization. This harmonizes the expectations of all stakeholders about the reason of the existence of the organization and about the probable future position that the organization wishes to achieve.

\section{Methodology}

The researcher succeeded in contacting associations, foundations, federations and confederations in Turkey. 16 of the questionnaires were not properly filled out, that is why net properly filled out number of questionnaires is 123 . The sample of the research is about 30 percent of the population given the whole population is around 400 .

Linear regression has been utilized in order to determine the effect of the independent variables of the study (environmental predictability and having strategy) the dependent variable (financial performance). Moreover, correlations have been used through Statistical Package for the Social Sciences (SPSS). The hypotheses of the study are as follows:

Hypothesis 1: Environmental predictability has a positive effect on financial performance of the NGOs.

Hypothesis 2: Having a strategy has a positive effect on financial performance of the NGOs.

Below are the tables of the results derived from various analysis. Regression Analysis has been implemented in order to determine the equation that explains the relation among dependent variable and independent variables.

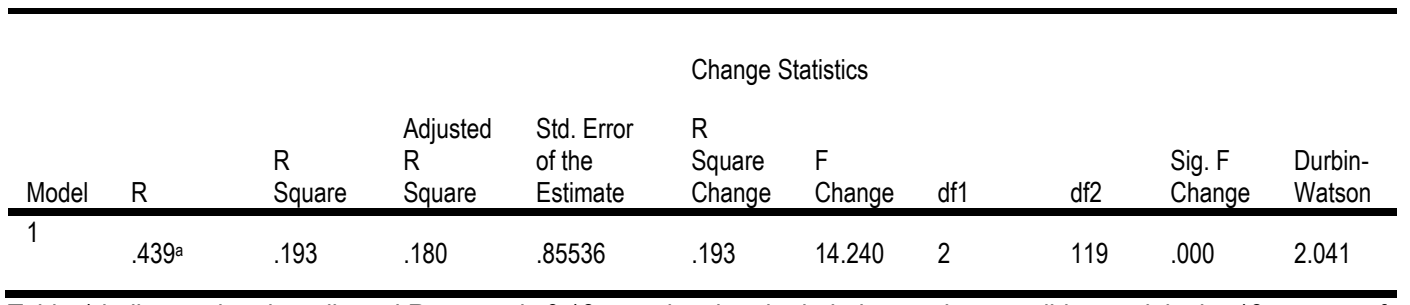

Table- 1 indicates that the adjusted $R$ square is 0.18 meaning that the indedepenedent varaibles explain the 18 percent of the total effect on quality. Durbin Watson figure will be mentioned below when analsysing the assumotions of regression. 
Table-2 ANOVA

\begin{tabular}{|c|c|c|c|c|c|c|}
\hline \multicolumn{2}{|c|}{ Model } & Sum of Squares & $d f$ & Mean Square & $\mathrm{F}$ & Sig. \\
\hline 1 & Regression & 20.837 & 2 & 10.418 & 14.240 & $.000^{b}$ \\
\hline & Residual & 87.065 & 119 & .732 & & \\
\hline & Total & 107.902 & 121 & & & \\
\hline
\end{tabular}

Table-2 indicates that the signifance of the model in general is .000 which is acceptable at the 99 percent confidence level.

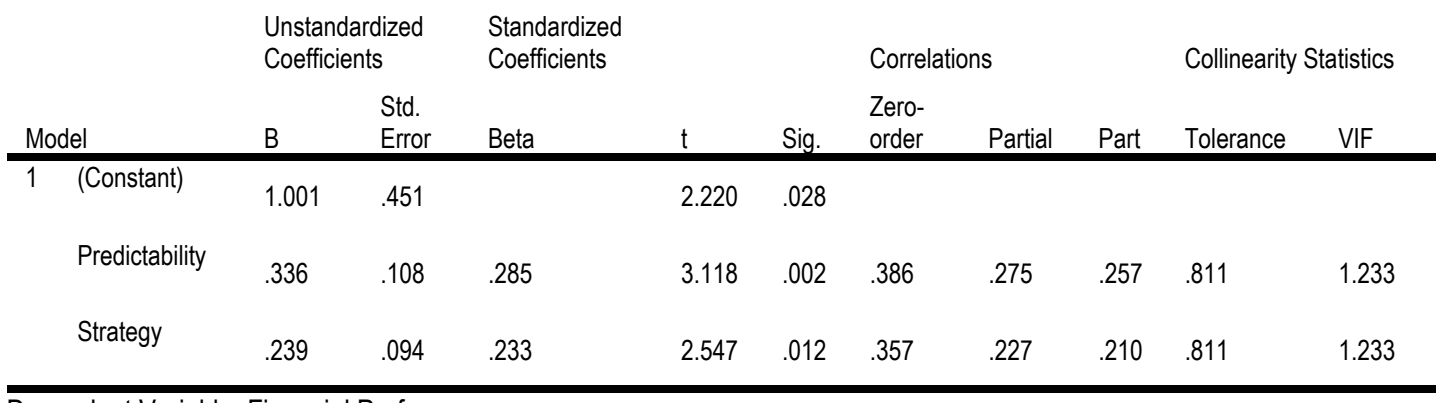

Dependent Variable: Financial Performance

Table-3 indicates that both Strategy and Environmental predictability have accapateble significance levels at the 99 percent confidence level.

So the regression function is

Quality $=1.001+0.336$ Environmental Predictability +0.239 Strategy

\begin{tabular}{|c|c|c|c|c|}
\hline & & FinancialPer & Predictability & Strategy \\
\hline \multirow[t]{3}{*}{$\begin{array}{l}\text { Pearson } \\
\text { Correlation }\end{array}$} & Financialper & 1.000 & & \\
\hline & Predictability & .386 & 1.000 & \\
\hline & Strategy & .357 & .434 & 1.000 \\
\hline
\end{tabular}

Table-4 indicates the correlations among all variables are positive but they are weak.

The assumptions of Regression model should be checked as well. The first assumption is normality assumption of the residuals. 


\section{Normality}

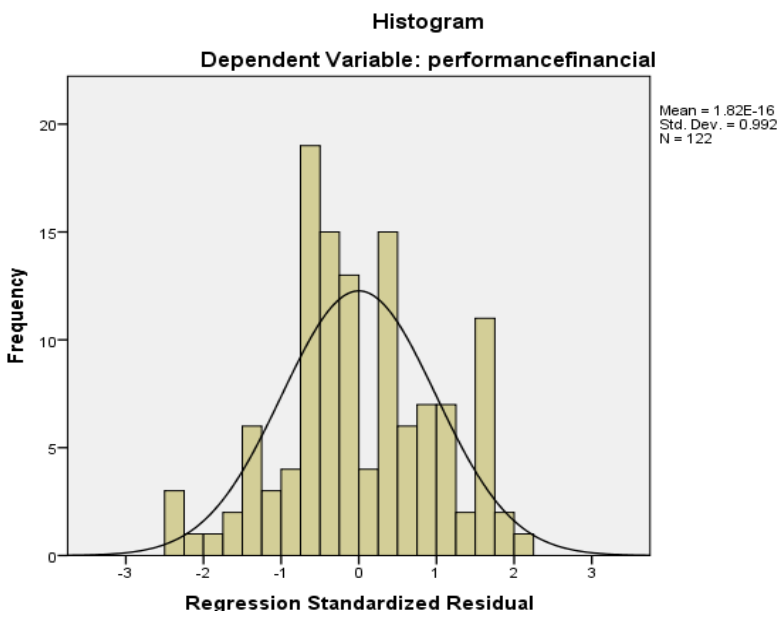

Figure-1a Normality

\section{Normal P-P Plot of Regression Standardized Residual}

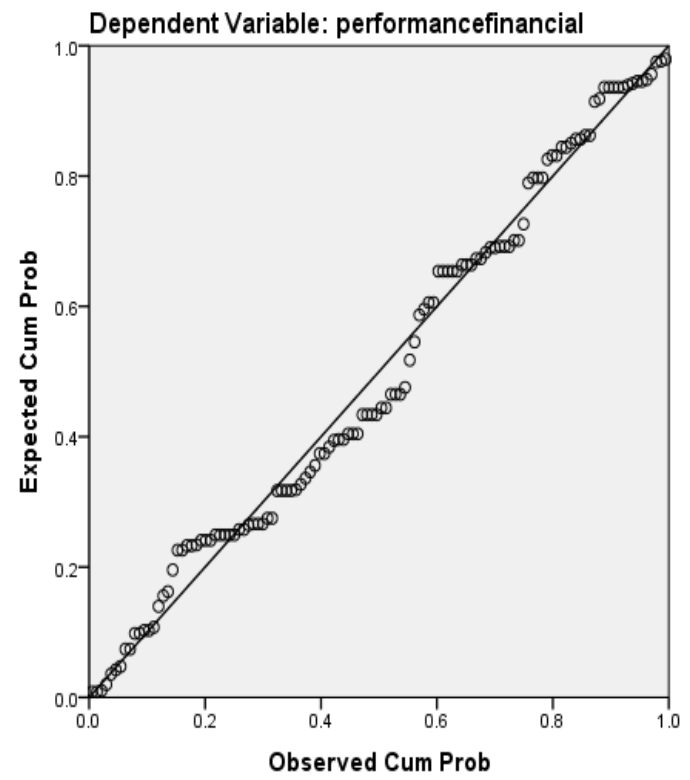

Figure-1b Normality

Given the figures above it can be concluded that the residuals are normally distributed.

\section{Multicollinearity}

Multicollinearity does not seem to be a problem because the VIF figures are 1,233 (less than 10) 


\section{Heteroscedasticity}

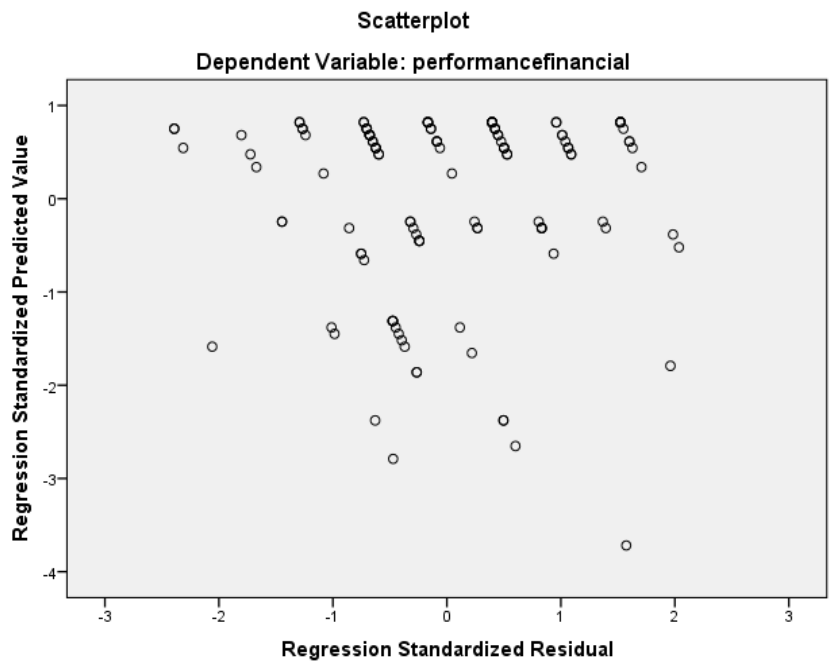

\section{Figure-2 Heteroscedasticity}

Checking the assumption with the graphs above, indicates that there is no problem regarding heteroscedasticity.

\section{Autocorrelation}

The last assumption to be focused on is autocorrelation assumption. If Durbin Watson test is applied the results below are obtained autocorrelation problem.

$\begin{array}{lllllllll}0 & \mathrm{dl} & \mathrm{du} & 2 & 4-\mathrm{du} & 4-\mathrm{dl} & 4 & \mathrm{~d}\end{array}$

$\mathrm{dl}=1.59$ (from Durbin Watson table)

$\mathrm{du}=1.65$ (from Durbin Watson table)

$4-\mathrm{du}=2.41$

$4-d l=2.35$

Here, our d value of 2.04 is between du (1.59) and 4-dl (2.35) so we don't reject the Ho which means there is no

\section{Conclusions}

\section{Discussion}

This study conceptualizes the dependent variable of the study financial performance as achieving the financial objectives which have been previously established. The first independent variable of the study environmental predictability is a subdimension of organizational environment that explains stability of the environment. The second independent variable, having strategy on the other hand is related with having mission and vision statements that are explicitly and clearly defined.

The results of regression analysis indicate that, environmental predictability and having a clearly defined strategy have positive effects on financial performance in non-governmental organizations.

The regression equation formulates the linear relationship among the dependent and independent variables. The choices of the participants indicate that one-unit increase in the instability of the environment (1-unit increase refers to 1 level shift of the opinion of the participants with respect to their agreement on the subject matter) will increase achieving the financial objectives which have been previously established in other words performance by 0.336 units. By the same token having 
mission and vision statements that are explicitly and clearly defined will increase achieving the financial objectives which have been previously established in other words performance by 0.239 units.

Correlation figures support the results derived from the regression equation that all three variables are positively correlated but the correlations are weak.

\section{Future Research Recommendations}

Even if there is a financial dimension of performance in every kind of institution either profit seeking or not, and financial aspect of performance measurement is very crucial, the future researches might focus on the non-financial aspect of the performance in the third sector that the sector in principle relies on the voluntary efforts of the members.

\section{References}

[1] Ansoff, H. I. (1972). The concept of strategic management. Journal of Business Policy, 2(4), 2-7.

[2] Chandler, A. D. (1962). Strategy and structure: Chapters in the history of the American enterprise. Massachusetts Institute of Technology Cambridge.

[3] Ilinitch, A. Y., D'Aveni, R. A., \& Lewin, A. Y. (1996). New organizational forms and strategies for managing in hypercompetitive environments. Organization Science, 7(3), 211-220

[4] Jones, G. R. (2010). Organizational theory, design, and change. Upper Saddle River: Pearson.

[5] Kaplan, R. S. (2001). Strategic Performance Measurement and Management in Nonprofit Organizations. Nonprofit Management \& Leadership, 11(3), 353-370.

[6] Koçel, T. (2011). İşletme Yöneticiliği, 13. Baskı, İstanbul: Beta Basım Yayın.

[7] Metin, H. (2017). Contingency Perspective in Non-Governmental Organizations (NGOs): LAP LAMBERT Academic Publishing (April 28, 2017) ISBN-10: 3330079762-ISBN-13: 978-3330079762

[8] Miles, R. H. (1980). Macro Organizational Behavior, Goodyear, Santa Monica.Cal.

[9] Mintzberg, H. (1979). The structuring of organizations: A synthesis of the research. University of Illinois at Urbana-Champaign's Academy for Entrepreneurial Leadership Historical Research Reference in Entrepreneurship.

[10] Ritchie, W. J., \& Kolodinsky, R. W. (2003). Nonprofit Organization Financial Performance Measurement. Nonprofit Management \& Leadership, 13(4), 367-381.

[11] Robbins,S.P(1983). Organization theory: The structure and design of organizations. Englewood Cliffs, NJ: Prentice-Hall.

[12] Tucker, B. Conceptualising Performance in the Not-for-profit Sector: a Tale of Two Theories (Doctoral dissertation, Routledge) Values and strategy in nonprofit human services. Nonprofi $t$ and Voluntary Sector Quarterly, 29 (1), 141-163. 